\section{Report of a workshop on problem-based learning and its implications for medical education in the UK

\author{
Held 7 June 1996 at the Royal Society of Medicine, London
}

\author{
Editors: J Bligh, P Wilkinson
}

This workshop was organised by the Fellowship of Postgraduate Medicine and combined plenary presentations from two international speakers with four 'case studies' of undergraduate curriculum change from the UK in devoted to group work and to discussion of the reports of these deliberations.

Dr Peter Wilkinson, Secretary of the Fellowship of Postgraduate Medicine, welcomed participants to the meeting, saying that this was possibly the first time medical educators in the UK had gathered together in such large numbers to discuss explicitly problem-based learning (PBL). He also reminded the audience of the vital role that Sir William Osler (a former President of the Fellowship of Postgraduate Medicine) had played, not only in reforming medical education in his own time, but also in introducing small group discussion as a teaching method.

\section{Medical education today - keeping up with a changing world}

Professor John Bligh began the meeting with a short presentation reviewing reasons for change in undergraduate medical education. He said that there is nothing more constant than change in medical practice, especially in the UK, and change in medical education at both postgraduate and undergraduate levels was no exception. He went on to describe effective learning as an active, constructive and organised process that works best when new knowledge and skills are built on those already acquired. Conventional medical school courses tend towards factual overload, with an emphasis on 'science' and clinical teaching based mostly in hospital settings which, combined with inappropriate assessment methods, leads to ineffective learning and considerable student stress. Modern teaching methods encourage students to be more active and to take greater responsibility for their own learning. PBL is one such approach that emphasises structured small group work based on clinically relevant problems. Using this approach students can learn basic science integrated in a clinical context right from the start of medical school. Students generate their own learning objectives within the framework of a group discussion, make extensive use of learning resources such as the library, lectures, practicals, computers the morning. The afternoon session was and expert teachers, and discuss their findings with each other after a period of self-learning. These discussions are animated, informed and productive. Students routinely evaluate their own performance and receive feedback from other students and the group tutor about their progress. However, despite considerable evidence and experience of PBL as an effective teaching method in medical education, it has not been taken up by British medical schools. Attitudes towards its use amongst medical educators appears to be polarised. The main purpose of the workshop was to examine some of this experience and evidence and to discuss what place PBL may occupy in the new undergraduate medical courses that are presently being designed around the country.

This report presents edited versions of the two keynote presentations, the texts of each of the four case studies, and a summary of the discussions that followed.

The experience of Harvard Medical School

Dr Miriam (Mimi) Wetzel, from the Office of Educational Development at Harvard Medical School (HMS), reported on lessons learned from 11 years experience of PBL at HMS.

She described the introduction of PBL as a pilot course known as the 'New Pathway' in 1985. Until that time the medical curriculum had been very traditional, with lectures, laboratory sessions and the occasional small group conference in a journal club format. With the New Pathway, lectures were cut to one hour per day, learning took place in small problem-based groups and the basic sciences were integrated across disciplines. The change process was not easy, not least because reputation at HMS was built on 'the number of Nobel laureates on the staff rather than on innovations in medical education'. Success in and leadership of a group of four Deans led by Daniel Tosteson who used educational retreats and symposia to seek the answer to the question "What are the knowledge, skills, and attitudes that will be needed by physicians in the $21^{\text {st }}$ century?".

Working groups of enthusiasts explored other curricula, receiving much encourageachieving reform was attributed to the vision 
ment from innovative schools such as the University of Limburg (The Netherlands), McMaster University (Canada), the University of Newcastle (Australia), and the University of New Mexico, Southern Illinois Medical School and Rush Medical College from the US. A Core Planning Group designed the new course, based on the previously identified knowledge, skills and attitudes, and medical educators were hired to develop educational materials. Frequent reports prompted widespread debate within the school but final approval for a new course was eventually gained and 24 freshmen volunteers were admitted in 1985 to a pilot programme. In fact there were more than 70 volunteers for the new course and a stratified lottery was needed to choose the new class. A further 38 students entered the next year and by September 1987, "opposition had diminished to the point where a Common Pathway was possible for all entering students". A new Medical Education Centre was also opened at that time to accommodate the needs of the curriculum.

The primary goals of the New Pathway were for the student to develop: a knowledge base characterised by breadth, depth, and flexibility; skills in the acquisition and use of knowledge with a commitment to lifelong learning, and sensitivity to the world of the patient. To implement these goals, the Dean and the curriculum planners decided that the new curriculum would have the following features: courses integrated across disciplines; decreased lecture time; protected study time; problembased learning using cases in small group tutorials; early contact with patients in the patient-doctor relationship course; a satisfactory/unsatisfactory grading system in the preclinical years. The decision to use PBL as the central, organising feature of the curriculum was crucial.

A typical week for a student at HMS was described. There are no scheduled classes on three days each week after 12.30 , allowing time for study and preparation for three problembased group meetings. This protected time is essential for learning basic sciences in the context of healthcare problems, and for effective participation in the group work. The group sessions are 1.5-2 $\mathrm{h}$ long and there are seven or eight students in each group. Laboratory sessions in histology and gross anatomy include sessions in radiology. Other laboratory sessions in year 1 may be devoted to pathology, genetics, and microbiology. Active learning sessions include mini case discussions with several short cases presented at the same time, and multi-station exercises with students moving in small groups through several stations and then presenting short cases with visual material to a larger group of up to 40 students. On one afternoon each week there is a required 'selective' course in one of the following areas:

Year 1: biostatistics/epidemiology or social medicine

Year 2: psychopathology or preventive medicine/nutrition
The other afternoon course is on patientdoctor relationships. In year 1, this is a twohour class focusing on history-taking skills with real patient interviews and observation, feedback, and guidance from a preceptor, and in year 2 the whole afternoon is taken up. Students spend days in hospital and outpatient settings towards the end of year 2 . Years 3 and 4 have the usual core clerkships in medicine, surgery, and women's and children's health, plus one month clerkships in neurology, psychiatry, and radiology. There is a onemonth advanced biomedical science requirement, a one-month advanced medicine clerkship, and ample time for electives in year 4 . Special attention is paid to ambulatory care in these core clerkships and a year-long primary care clerkship is being phased in for all students in the 1996/7 academic year.

HMS has 11 years experience with the 'new' curriculum. The original programme has been continually reviewed and updated to meet the needs of students in an ever-changing world. Curriculum design groups headed by a course director, work closely with faculty members and an educator to plan, evaluate, and improve the course and to keep the original vision alive. Many lessons have been learned over the 11 years, and these include:

- a leader with vision and courage is essential

- there are always faculty who love to teach and will do so in spite of extreme demands on their time and energy

- a programme of faculty development is necessary to enhance teaching skills and increase the number of trained teachers

- educators are essential

- trust the faculty - they will teach thoughtfully and well

- trust the students - they will learn

Finally, Dr Wetzel described some of the characteristics of the medical students. Slightly more than half are female, and slightly more than half are from minority groups (African American, Hispanics, Asian, Native American). The students "have been doing well on National Board exams throughout the 11 years of problem-based learning, entering and performing well in residencies, and clearly exhibiting a joy and excitement in their study of medicine that should serve them, and their patients, well throughout their medical careers".

In the discussion that followed questions were raised about student motivation, the resources required in a curriculum of this nature, the effectiveness of PBL, assessment, and the role of lectures. Dr Wetzel replied saying that "motivation in education is just about everything" and one of the great features of PBL was its ability to offer something to students at all levels. Assessment was described by Dr Wetzel as the "great unsolved area of medical education". At HMS they use very few multiple-choice exams, preferring case-based assessments, although the number of exams has decreased over the years because "time spent in exams is time that could be better spent in learning". In addition, the students are continually assessed in the groups by their 
peers, and by the tutor. Students receive a course pack that includes recommended reading and photocopies of selected 'core' reading materials and rarely have problems with overdemand of other resources. The students value lectures and the lecturers are told not to include material that can be found in textbooks. The balance and content of lectures to other learning activities, for example, lab sessions, is reviewed each year. In terms of other resources, time is the most expensive commodity of all, but once the initial start-up period is over the programme costs about as much as a conventional one to run. After the early discussion periods, the basic planning took about two years and there was a 'mad rush' at the beginning of each year. Whilst there is a need for more good quality research about the impact of PBL on student learning, there is no evidence that a standard lecturebased course is the best approach.

\section{The research base of problem-based learning}

Professor Cees van der Vleuten from the Department of Educational Development and Research at the University of Maastricht presented a paper describing some of the evidence for the effectiveness of PBL. Before presenting a review of the evidence, Professor van der Vleuten started by outlining the curriculum and describing how students learn at Maastricht.

The programme is organised so that clinical and basic sciences are integrated in blocks or modules. Patient contact starts very early, with students learning clinical skills (for example, blood pressure measurement and bandaging) on each other and practising their communication skills with patients; self-study plays a very large part in learning. Students work with a tutor in small groups of eight, and elect a chairman and recorder for each session. The sessions take about two hours with the first hour spent on reporting back on previous problems and the second defining new learning objectives. The students use many facilities and resources for independent study and then report back and apply their new knowledge to the original case. The tutorial group is the heart of learning. Lectures are used to tackle a particularly difficult topic, to add structure to the course or to motivate staff (“They love to lecture!'). Every three weeks students have a contact with a simulated patient and practise communication and history-taking skills using a video recording for subsequent group discussion with a behavioural scientist and a clinician. Other first-year contacts include attachments to general practice, and the midwifery and ambulance services. Self-study is a very important part of the curriculum and there are many facilities provided for this, including additional library space. Professor van der Vleuten said that education is more about learning than it is about teaching. Essentially, teachers are the manufacturers or managers of learning and the curriculum reflects this broad approach in creating a supportive learning environment for the students. He then went on to describe some of the evidence they have gathered about the outcomes of learning in a problem-based course. He described the 'progress test' each student does every three months - each of the 200 students in each of the six years sits the same exam at the same time. First year students are able to answer only some of the questions, second year students do a little better and so on until final year. This approach was introduced in an attempt to disengage testing from learning, that is, by asking students to sit an exam for which they could not practically revise, the effects of the exam on the learning they were doing in the course at the time should be minimised. Scores obtained by students increase each time they take the test and, compared to reference groups from other Dutch universities, students in the problembased course do just as well by the final year. However, even earlier in the course, students in the PBL course are scoring comparably to those in other Dutch medical schools. This is also true of tests of problem-solving which causes some problems as PBL is thought to be a method for improving problem-solving skills.

In the case of clinical skills the situation is different. There are major differences in years four and six between the Maastricht students and those of other schools. Also, the drop-out rates from the PBL course are considerably lower than those of peer schools $(<10 \%$ compared to a national average of around $30 \%)$. Clinicians sometimes report that Maastricht students have gaps in their knowledge but when they are compared in experimental conditions with peer groups this is not substantiated - they are, however, quick at filling any gaps that are found and, the progress test demonstrates that they continue to learn about basic sciences in the clinical years.

The average study time at Maastricht is 6.2 years while at national level it is more than seven years leading to the claim that the school is producing more doctors in less time and at the same level of knowledge as others. There are no differences in career choice (although this is confounded by the influences of the job market in a small country) but there are differences in library skills and use of the library that continues after graduation. A dominant and consistent finding is that students in PBL have much more fun and are more motivated than their peers from traditional schools. The resources available to the medical school at Maastricht are the same as those at all other Dutch schools.

This paper generated a lot of discussion with a number of speakers commenting on how their anxieties had been addressed and about the excitement they felt on hearing the description of the course. There were many questions, in particular on the lack of longterm evidence about effects on clinical practice, the importance of having experienced teachers, early anxiety on the part of students about how much to learn, about the group 
process, the importance of students working together rather than in isolation for grades, and the influence of selection on student intake.

Four case studies of curriculum reform in the UK

\section{PBL AT THE MEDICAL SCHOOL, THE UNIVERSITY OF GLASGOW}

Professor Iain Percy-Robb presented this description of the changes being introduced across the whole curriculum at Glasgow. The new course starts in October 1996.

Subject to final approval by the University Senate the Medical School in Glasgow will introduce a radically revised undergraduate medical curriculum in October 1996. The new curriculum will consist of six parts.

- the Core

- vocational studies

- special study modules

- the Clinical Core

- electives

- intercalated degrees

The new curriculum will be studentcentred, PBL being used throughout the Core and being continued into the Clinical Core when that comes on stream in 1999.

The Core, which will start in first year and continue into year four, consists of four rounds of learning during which the students will revisit subjects, being presented in successive rounds, with clinical scenarios that incorporate both reinforcement of learning and increasing intellectual challenge. The first round will be broad based and will introduce the students to the importance of the individual and the perspective of the patient; molecules and tissues will be the emphasis in round two; clinical systems in round three, and in round four, clinical symptoms will be emphasised. Throughout the Core, learning goals will be set by the students, using clinical scenarios as the basic material. It is an important aspect of the curricular plan that the natural curiosity of the students be developed and that the students should become independent learners.

We have also developed a 'hierarchy of systems' which will provide a mechanism which students will use for organising knowledge and a checklist to ensure that they examine several dimensions of each problem rather than focusing exclusively on one, as follows:

\section{Hierarchy of} systems

\section{Societies}

Groups

Families

The individual

Major body systems

Tissues and organs

Cells

Organelles

Molecules a series of Learning Resources that are carefully co-ordinated with the content of the clinical scenarios and will include a small number of lectures: students in the present first year have a total of 311 lectures and the new first year will have 30 .

These changes in our curriculum are being made partly in response to the recommendations of the General Medical Council contained in 'Tomorrow's doctors'. Other medical schools are also involved in similar, and in some cases as far-reaching, changes in their curricula. It follows that virtually the whole of undergraduate medical education in the $\mathrm{UK}$ is in a state of flux. It is therefore important to recognise that young doctors who will be entering postgraduate medicine in a few years time are likely to be significantly different people from recent medical graduates.

All students are being trained to manage their own learning, and to act as critical consumers of education. They will be used to programmes of education that have taken advantage of learning systems informed by modern educational theory. They will be used to systems of assessment that are selected to encourage learning skills and to reduce the emphasis on the uncritical acquisition of facts. No doubt the Royal Colleges have anticipated these very welcome developments and have in hand the necessary revision and development of their curricula.

\section{PBL: the Glasgow steps}

\begin{tabular}{|c|c|}
\hline Process & Outcome \\
\hline $\begin{array}{l}\text { Interpret the } \\
\text { situation }\end{array}$ & $\begin{array}{l}\text { First definitions of terms and } \\
\text { clarification of meaning } \\
\text { Recognition of key features } \\
\text { Situation is described by } \\
\text { learners in their language }\end{array}$ \\
\hline $\begin{array}{l}\text { Generate } \\
\text { explanations }\end{array}$ & $\begin{array}{l}\text { Production of existing } \\
\text { relevant knowledge } \\
\text { presented by group } \\
\text { members }\end{array}$ \\
\hline $\begin{array}{l}\text { Define the } \\
\text { problem(s) }\end{array}$ & $\begin{array}{l}\text { Statement by learners of the } \\
\text { problem(s) that they as a } \\
\text { group decide to 'take on } \\
\text { board' }\end{array}$ \\
\hline $\begin{array}{l}\text { Identify a } \\
\text { strategy for the } \\
\text { enquiry }\end{array}$ & $\begin{array}{l}\text { Identification of the } \\
\text { additional information and } \\
\text { understanding that is } \\
\text { needed }\end{array}$ \\
\hline $\begin{array}{l}\text { Decide a strategy } \\
\text { for the enquiry }\end{array}$ & $\begin{array}{l}\text { A plan which details how } \\
\text { answers to questions will be } \\
\text { sought }\end{array}$ \\
\hline $\begin{array}{l}\text { The Enquiry } \\
\text { Pool and test new } \\
\text { knowledge }\end{array}$ & $\begin{array}{l}\text { Individual knowledge } \\
\text { contributions integrated } \\
\text { where appropriate } \\
\text { Different conceptions and } \\
\text { misconceptions are con- } \\
\text { fronted and resolved as far } \\
\text { as possible }\end{array}$ \\
\hline $\begin{array}{l}\text { Reflect on the } \\
\text { adequacy of the } \\
\text { answers and } \\
\text { appropriateness } \\
\text { of questions }\end{array}$ & $\begin{array}{l}\text { Learning gain (of content) } \\
\text { Recognition of when a } \\
\text { return to step } 4 \text { is needed }\end{array}$ \\
\hline $\begin{array}{l}\text { Reflect on the } \\
\text { group process }\end{array}$ & Learning gain (of process) \\
\hline
\end{tabular}

Box 2 shown in box 1. Students will meet twice weekly, for two hours on each occasion, with a trained facilitator. Having established their learning goals, they will have available to them
- the most basic systems are molecular ones

- the cell is a complex system

- tissues and organs behave as systems

- we are familiar with the concept of body systems (cardiovascular, etc)

- families, too, can be thought of as systems

- communities, populations and societies are often understood and analysed as systems

Hence we arrive at the hierarchy of systems group process 
The development of the new curriculum has fallen to a large number of academic colleagues, including members of the Curriculum Planning Group. The contributions by $\mathrm{Mr}$ David Lloyd, Curriculum Development Officer and Mr Colin Holroyd, The Teaching and Learning Service, Glasgow University, in developing the educational infrastructure of the curriculum, are acknowledged.

\section{A PROBLEM-ORIENTATED CURRICULUM - AN EVOLUTIONARY APPROACH}

Philip Brown from St George's Hospital Medical School discussed the approach being taken in London, again a programme starting in 1996.

At St George's Hospital Medical School we are not introducing a totally problem-based curriculum. We are, however, starting a new curriculum this October which we have described as 'problem-orientated'. In this paper I will explain what this means, explore some of the justifications for the evolutionary approach we have taken, suggest some advantages and disadvantages of this approach and outline some 'principles' for evolution.

\section{What does a 'problem-orientated' curriculum} mean?

- An underlying educational philosophy of 'directed self-learning', meaning that the learning objectives for the students are set by the staff, but the student takes responsibility for achieving them

- A bank of 'key cases' - the common and important cases which general practitioners and pre-registration house officers encounter. Students will cover all of these key cases during years 3 and 4 , and some of them will be used illustratively in years 1 and 2 . The key cases include specific learning objectives.

- PBL will be used in various forms by some of the modules. There is no central dictation about this.

- Weekly PBL tutorials. These aim to give an overview of the whole course, and help with the process of developing student's independent learning capacity and their critical skills. The tutorials are based around a short scenario, itself being based on one or more of the longer key cases, although it is a much more general situation, and it includes four 'learning areas' to guide the students' discussion. After a brief introductory clinical seminar which sets the scene and poses some questions in students' minds, the scenario is discussed in three tutorials, held weekly. The tutors are 'facilitators' of the learning, not experts there for teaching. They stay with the same group of students (approximately eight) through the whole year. Every three weeks, a new scenario is tackled.

Why not adopt a fully 'problem-based' curriculum? We have elected not to adopt a fully problembased curriculum for three main reasons:

- the disruptive nature of radical change
- concern over resources. Do we have enough staff and enough teaching space to cope with small-group facilitative learning on a large scale?

- scepticism of many staff towards the educational basis of PBL

\section{Theories of introducing change}

These may explain why the evolutionary approach to change is the most common. I will start with some of the basic values which are espoused in universities:

- individualism and academic freedom

- curiosity - the drive to find out more and develop

- conservatism - the opposite force which requires proof

These create the 'bottom-heavy' enterprise described by Burton Clark in 1983. Inevitably, in such an organisation, with so many centres of interest, power and initiative, incremental change, not radical change, is the norm. This 'incrementalism' was fully described by CE Lindblom in a 1959 article called The science of muddling through. Lindblom maintained that change had to be incremental, because of the complexity of competing interests and of unknown outcomes. He argued that, in practice, means are not chosen after ends, but that both are developed simultaneously. 'Muddling through' is not meant to be a perjorative term, rather a realistic description of what always happens. However, I suspect that his tongue was at least partly in his cheek because his ideas developed in a later paper called Still muddling, not yet through. This approach has been criticised as excessively pragmatic, conservative and unsuited to occasions requiring radical change. But Lindblom has countered by arguing that largescale changes did and should occur through a succession of small steps. Concentrating on these small steps, rather than the grand design, he said, should avoid large and costly mistakes. Indeed, in an empirical study undertaken in the early 1980 s of various types of changes introduced into higher education across Europe, Cerych and Sabatier concluded that wide-ranging and fundamental reforms were not the most effective types of change.

In 1992, Tony Becher and Maurice Kogan conducted an analysis of how higher education works in the UK and concluded that coercive changes are inherently unstable. They may produce operational compliance (the appearance of doing what you want), but normative rejection (no belief in it), and ultimately this will lead to collapse. They argue that we should mediate between the values of the changes we are introducing and the internal values the people in the organisation already hold. They describe this as a process of learning.

PBL is an educational approach which stresses the autonomy of the individual and the need for the learner to 'own' the subject rather than just memorise it. It would be strange if we tried to implement such an 
approach without a similar process of learning and 'owning' the change occurring in the staff. Radical change may be able to achieve such ownership, but evolution is probably a model better suited to achieving it.

The evolutionary approach to $P B L$

The evolutionary approach views implementation as a learning process, not an organisational project. In other words,

- explore the idea of what PBL is

- gain acceptance of this idea among staff

- test the practicalities of implementing PBL

- evaluate this experience, and start the loop again.

The advantages and disadvantages of PBL are shown in box 3. The principles of evolutionary PBL are given in box 4 .

\section{STAFF DEVELOPMENT FOR CURRICULUM REFORM}

The Reverend Dr David Taylor described the approach being taken at the medical school in Liverpool to provide staff training for tutors and others involved in their new problem-based curriculum due to start in October 1996.

The medical school at the University of Liverpool, which has a well-established and successful traditional medical course, is adopting a new curriculum with a high level of problembased learning. This paper will address some of the issues tackled in the staff development programme, and indicate an approach which has proved itself to be successful in addressing our main aims.

It is clear to most people involved in medical education that some form of curriculum reform is necessary, and in some cases long overdue. Such reform is threatening because it has implications for our established patterns of work and study. It has implications for the management and financial structures under which we work. It also causes us to look back at the undergraduate education that today's doctors received. These problems affect different people in different ways, and any programme for staff development must allow the issues to be tackled in a safe environment. For established staff in particular, staff development can also be perceived as threatening, but it is absolutely essential if curriculum development is to progress.

The aim of any staff development programme, whether explicit or implicit, is twofold. Clearly, there is the apparent purpose of the exercise, in this case to provide prospective tutors with the knowledge, skills and experience they need to be able to handle PBL tutorial groups with confidence. The second aim, which is at least equally important, is to enable a change in the attitudes of staff or the corporate culture.

The Liverpool staff development programme for PBL started in October 1994, two years before implementation of the new curriculum. It has three phases. As many prospective tutors as possible were invited (or in some cases nominated by their Heads of
Advantages and disadvantages of evolutionary change

Advantages

- PBL is done by enthusiasts, not saboteurs!

- it needs fewer resources at the start

- there is less risk of making big mistakes

Disadvantages

- PBL is low-profile, and so may attract fewer resources, less attention and therefore fewer 'converts'

- students may discount PBL as an unimportant 'add-on', or an 'inefficient' way of learning

Box 3

\begin{tabular}{|l|}
\hline Principles of evolutionary PBL \\
\hline - encourage enthusiasts \\
- dllow innovations \\
- don't overstretch the interested but \\
- encommitted \\
- provide training \\
- evaluate and re-design \\
- involve and brief the students \\
- make PBL sessions of broad interest and fun \\
ensure that PBL work will be rewarded in \\
assessments
\end{tabular}

Box 4

Department or senior partners) to attend an Introductory day at which the new approach would be outlined. The prospective tutors were drawn from the current teachers of the undergraduate curriculum and also other general practitioners and hospital clinicians. Attendance at the Introductory day was essential for anyone who wished to be involved with the PBL tutorials. Each Introductory day has between 10 and 14 participants, and in the period up to June 1996 almost 500 prospective tutors have undergone the process. Following the Introductory day, prospective tutors were invited to apply the process to their existing teaching, or to attend one of a number of practice sessions, which we set up with final year students. Over 50 tutors have attended group sessions organised by the faculty. In addition to this we have arranged regular monthly lunchtime training sessions covering various aspects highlighted by the trainees.

The Introductory day started with a talk, during which the principles behind learning in groups, and the Maastricht and McMaster models of PBL were outlined. We then showed a video of a PBL tutorial and invited brief discussion. Prospective tutors were then split into groups of six to eight persons and each group had, as a tutor, a member of staff who was experienced in PBL and had been to either McMaster or Maastricht. The group was given a case to study, using the Maastricht SevenStep Process. Our intention was to allow the groups to understand the reasons for PBL by active involvement in the process. In the early days we chose a case which was, in retrospect, ill-conceived. 
'You are a head of department. Faculty has decided to introduce problem-based learning tutorials into the medical course. You have to explain the implications to your department'.

This case provoked long and sometimes acrimonious debates about funding and resourcing issues, and it required a great deal of skill on the part of the tutor to ensure that the group dealt with the wider problem. The case was subsequently changed to

'The Principal of a local Sixth-Form College has heard that the Medical Faculty is going to adopt problem-based learning in 1996. The Faculty receives a number of students each year from her college. She is Chair of the region's Sixth-Form Teachers and College Association and would like to know more about this new initiative. She has invited a representative from your group to speak about this aspect of the new curriculum'.

We had prepared a collection of multiple copies of important or interesting papers and documents which related to PBL approaches, course outcomes, and follow-up studies. Over lunch the groups used those resources to do their research. After lunch we ran a second 'tutorial' session, at which they reported back to the group. We then held a plenary session, inviting comment, and encouraging people to develop an action plan, indicated where and when they would apply their new-found skills and what help they would require. We suggested that they paired up with colleagues and compared notes on their experiences, but this was only acted upon by a very few of those who decided to go further. We evaluated the sessions, and that study is published elsewhere. Seventy-nine prospective tutors expressed an interest in practice-sessions with final year students, and we have been able to give 55 experience of working with small groups. Many more have incorporated it into their existing teaching methods, and there is now a high level of enthusiasm and expectation amongst those who wish to be involved in teaching on the new curriculum.

An important part of the staff-development programme is the regular series of monthly lunchtime training sessions. These usually take the form of a video presentation, followed by, or interspersed with, discussions. We provide literature for people to take away, and lunch. Topics covered in these sessions have included different PBL styles, dysfunctional groups, evaluations, giving and receiving feedback and, of course, practice tutorials with other tutors taking the place of students. Future sessions will include the cases to be covered in the first two semesters of the course, and a debriefing session at the end of each semester.

Each of the training sessions is subject to evaluation, but in addition we are running a study which aims to evaluate changes in staff attitude. Initial inspection of the early results of the study show that attitudes are either soft- ening or changing towards PBL. Many people had serious reservations about PBL at first, although some (particularly general practitioner trainers) had been using it for several years. Two of the comments received are echoed by this author: "I feel much more at one with PBL than I did a year ago" and “Help, it's getting close!".

It is clear from this study that any programme of staff development needs to take attitudes to change very seriously, and that consequently, staff development programmes need to be long-term. It is essential to listen to people, and try to give them the training they perceive they need. The process of active learning, and the whole idea of a 'metaproblem', has been very successful. We have, however, found it very difficult to engender enthusiasm for the training process in our final year students, and consequently it has been difficult to allow as much practice of PBL tutorials as we might have hoped.

The author would like to thank all those who have been involved in the Staff Development programme within Liverpool University Medical School, especially Professor John Bligh, Mr Phillip Evans, Dr John Smith and Ms Liz Jump.

PROBLEM-BASED LEARNING - THE MANCHESTER EXPERIENCE

Dr Paul O'Neill presented a description and some evaluation data about the new course at Manchester. This has been up and running successfully for two years and students were just about to enter their clinical years.

In 1994, Manchester became the first medical school in the UK to change to an entirely PBL curriculum. In years 1 and 2 , each semester has an overall theme based on the Health of the nation (nutrition and metabolism, cardiorespiratory fitness, the life cycle, and abilities and disabilities). The semesters are managed by a multidisciplinary team. The students meet three times a week for one-hour sessions to discuss a problem with a facilitator. In addition, there are approximately 10 hours of scheduled events (practicals, dissection, lectures) as resources for the trigger material. New integrated assessments have been designed to address the objectives for the course.

We have achieved curriculum reform with no increase in staff. The approximate PBL group size is 14 , but we have found that the students often prefer to divide into two smaller groups, with one facilitator helping both during the session. We also have clinical co-tutors acting as resources to groups and providing some limited clinical exposure. There has been a five-fold increase in use of the library. Similarly, we have experienced a large demand for access to information technology and the students have required support in using this.

Overall, the changes have been well received; the number of students leaving the course has fallen and there has been a rise in the proportion of students who like this 
method of learning. In terms of specific objectives, these have been achieved for most students; less than one in 20 feels unsure of working in groups, with similar small numbers lacking in confidence in setting objectives, directing their own learning and accessing resources. The major problem is the lack of confidence students feel about using information technology.

We are continuing with PBL in years 3 and 4. In order to achieve vertical and horizontal integration, we have used as reference points, Index Clinical Situations (ICSs) which a new undergraduate must have competence in managing, either on their own or as part of a team. After extensive consultation, a list of 206 ICSs was agreed on, which comprised 56 symptoms or signs and 150 diseases, syndromes or clinical problems. Each of these was then broken down into core knowledge and skills.

During the first two years of the new programme, $150(73 \%)$ of the ICSs are touched on or covered to some extent in the working problems. This includes 48 (23\%) ICSs as the primary foci of the cases. Thirteen (6\%) have been covered to some extent more than five times.

There are four core modules in years 3 and 4 , each with an overarching theme which builds on the corresponding theme from years 1 and 2 (eg, 'cardiorespiratory fitness' in year 1 and 'heart, lungs and blood' in year 3). Each module is managed by a multidisciplinary team. All of the ICSs have been apportioned between the four modules. The working problems are being developed from the ICS using the criteria of $(a)$ the 56 ICSs $(27 \%)$ that have not been covered previously; (b) the ICS needs to be revisited to increase knowledge and understanding. For each working problem, the design team utilise the core knowledge and skills identified for overlapping ICSs (eg, 'chest pain' and 'ischaemic heart disease') to develop the objectives used to design the trigger material. Using this method, we can ensure that the core content is covered and can map where any particuiar clinical situation, item of knowledge, or skill is triggered.

As with the first two years, the student week is focused on a working problem. The PBL group size is smaller (eight) and each group has a tutor who is medically qualified. The tutors have attended staff development workshops. The PBL group meets for an hour to discuss the working problem and then a week later for one and a half hours to share their learning. There are no formal lecture courses for the students, although there are workshops and seminars as resources that they can access. The steps that students use to work through problems have been amended to encourage links between clinical experience and the trigger material.

Our experience so far in Manchester has been very positive with a high level of student and staff satisfaction. We are now looking forward to continuing with PBL in a clinical setting.
The discussion that followed focused on assessment of students, including the use of peer assessment within PBL groups, resources (again), especially for teaching in the community, how to recruit and train enthusiastic teaching staff, use of sixth-form students in staff training, increasing interest in intercalated degrees, identification of the 'core' syllabus, and the impact of PBL courses on subsequent career choice.

\section{Conclusions}

PBL is an important approach to teaching and learning in medicine. It is an approach based on sound educational principles that encourages students to take responsibility for their own learning. A considerable body of literature about PBL, including several major review articles, has been published in the international literature. Using PBL, students acquire facts and skills and perform at levels comparable to those of their peers in conventional courses. In at least one medical school, after start-up costs, the costs of maintaining courses using PBL are similar to those of conventional teaching. From a starting point as an innovative teaching method introduced to a new medical school at McMaster Medical School in Hamilton, Ontario, Canada, in the 1960 s, it has been successfully introduced into medical schools across the world, although the balance has mostly favoured new schools over those with conventional courses. Until recently, PBL has not found a place in undergraduate medical courses in the UK, and this workshop was convened to address some of the issues involved in introducing PBL during a period of general curriculum renewal recently stimulated by the General Medical Council.

This was the first meeting about PBL in the UK and brought together over 100 people who had either started or were just starting to introduce PBL into the undergraduate curriculum, alongside those who were interested in the concept. Two international experts added considerable depth to the discussions with their extensive experience in this area.

For many decades medical schools have taught medicine in the same way. Although change is underway students are still fed large amounts of information in passive formats which they are then meant to regurgitate at the time of examinations. The amount of information students are given was already recognised as excessive over a century ago and inevitably has increased since. The balance between the basic science and clinical components of an undergraduate course can be related more to the influence of departments than the needs of the students, and as these components have been taught separately in the past there has been a lack of understanding as to how they related to each other.

PBL attempts to change this philosophy by handing the responsibility of much of the learning to the students and, by providing them with a format and a basic set of questions, allows them to search for the answers themselves thus providing active learning. 
A student-centred, developmental philosophy of education, with an emphasis on active rather than passive educational methodology can result in benefits for students everywhere

Before embarking on such a major change, most academics in the UK would wish to have evidence that PBL will provide a better doctor, or at the very least a more motivated student. However, looked at from another perspective, do we know that the present lecture-based format is 'the best'? As with so much of educational research the answer is only partial but the meeting heard that students at Maastricht, after taking into account selection bias, have better clinical skills, a lower attrition rate, a shorter course, are quicker at remedying gaps in knowledge and are more effective at working in teams than comparable students in other schools. There are no long-term data on how these attributes develop during clinical practice.

If a school or university wants to make the change it will need to have a strong visionary opinion leader who will push the process forward and will engage the attention of a critical mass of staff sufficient to create an unstoppable momentum. A core planning group, including specialist educationalists, will be needed to plan the new curriculum and develop educational materials. The planning phase should not be too prolonged, although we have learnt that it took two years at Harvard. Whether PBL can be grafted onto a traditional course to make a more 'learnercentred' course rather than making a complete change is uncertain but the experience at St George's Hospital will help inform that debate. Part of the rationale for doing it in this way was a belief that large-scale changes should occur through a series of small incremental steps.

Lack of resources is often stated as a reason why a change to PBL cannot be made but the meeting heard that, although extra resources will be needed, these are often to do with boosting the library facilities, with the use of these increasing five-fold in Manchester. Staff time will be needed during the development phase but if spread over the whole faculty this will be individually relatively small.

Change is possible, even in a highly traditional university, and the process can be exciting and rewarding for both faculty and students

The planning group will need to co-ordinate the various departments, who may have worked semi-autonomously in the past, and create an integrated curriculum which brings together basic science and clinical medicine in a coherent way. Staff will need training, supporting and guiding in the new methodologies with a staff development programme and, as in Liverpool, this will have to start some time before the course changes and continue after it has started. Reform is often threatening and therefore it is important to tackle the issues in a safe environment. At Maastricht, the teachers have to go through an elaborate faculty development programme and are frequently evaluated.

Trust the faculty!

A set of key or core cases can be helpful and these will need to be carefully constructed to steer the students to ask appropriate questions which will cover the needs of the curriculum. The core content should avoid a long list of items and may be best defined in terms of problems, not disciplines. This particular wheel does not have to be completely reinvented - it should be possible to tailor the questions from another institution.

Do not re-invent the wheel; copy it, adapt it to your own needs and subsequently share it

At Manchester, over 200 cases were created after wide consulation involving the profession, the community and management, with specific input from patients. Writing objectives for the course can be a good exercise for case writers and it helps if the cases contain some drama to catch the student's attention. The small groups the students use to debate these questions will often need a faculty member in the initial stages to occasionally guide the group and help with the initial insecurity of group members as they come to grips with this style of learning.

The tutorial group is the heart of the matter

One format for a group is a session lasting for two hours with an hour spent on reporting back the answers to the questions raised in the previous case discussion with a further hour spent on a new case. These case studies are at the core of PBL and will have to be carefully reviewed and refined according to experience and their relevance in view of changes in medical practice.

The questions raised by the students will usually be answered by self-enquiry and, as mentioned previously, library resources will have to be boosted to cope. Additional course material can be provided - at Harvard they provide about 20 key papers and a couple of articles from textbooks. Concerns were raised at the meeting the PBL would lead to gaps in knowledge of clinical importance but the experience in Maastricht is that this is not the case; this is backed up by the finding that their students handle external examinations as well as students at another medical school in Holland.

Trust the students!

PBL does not lead to the abandonment of lectures, although in Glasgow the number will fall from 311 to 30 a year. At Harvard there is a one-hour lecture every day but the lecturers are asked to incorporate material and concepts that they do not think will have been covered in the group sessions. Alongside these core activities Maastricht provides the usual skills - laboratory work, training in communication, simulated patient contacts with behavioural 
scientists, and health practice contacts such as primary care and the ambulance service.

Assessment in medical education is acknowledged to be challenging. Case-based examinations are hard to grade and hard to construct. An advantage of PBL is that it gives the facilitator of the groups a much greater exposure to individual students and therefore the chance to take corrective action if this is deemed necessary. Glasgow is using several formats including objective structured clinical examinations, a written assessment and a 'medical independent learning exercise'.

Assessments should be tailored to the objectives of the curriculum otherwise assessment will dominate

PBL has been shown to have numerous advantages in educational terms over the traditional passive approach to medical education and, in practice, produces practitioners who are more self-motivated and capable of keeping informed during their professional career through self-education. The meeting heard that PBL is now being introduced into several medical schools in the UK and, if these initial changes prove

\section{List of delegates}

Mrs M Allen, Department of Postgraduate Education, Seacroft Hospital, Leeds

Dr PLR Andrews, Reader in Physiology, St George's Hospital Medical School, London

Mr B Bailey, Nurse Tutor, Lothian College of Health Studies, Edinburgh

Professor BEC Banks, Department of Physiology, University College, London

Dr AF Barron, GP teacher/trainer in primary care, Winchester

Dr NT Bateman, Assistant Clinical Dean, St Thomas' Hospital (UMDS), London

Dr GF Batstone, Director, Medical Development Programme, King's Fund, London

Dr PR Beck, Medical Director, Rotherham General Hospital, Rotherham

Dr C Bielanski, Consultant Physician \& Sub-Dean, Whittington Hospital, London

Dr TL Bigge, Brannan Medical Centre, Barnstaple, Devon

Dr A Bimbashi, Visiting Doctor, Royal Free Hospital, London

Professor JG Bligh, Liverpool University Medical Education Unit, Liverpool

Dr P Bradley, Medical Education Unit, Royal Liverpool Hospital, Liverpool

Mr P Brown, St George's Hospital Medical School, London

Dr J Burton, Associate Adviser in General Practice fo CME, TPMDE, London

Professor YH Carter, St Bartholomew's \& Royal Hospital School of Medicine, London

Dr F Carter, Department of General Practice, Imperial College/St Mary's Hospital, London

Dr LC Chan, University of Hong Kong, Hong Kong

Dr RD Churchill, Department of General Practice, University of Nottingham Medical School, Nottingham

Ms HP Clay, Acting Deputy Academic Registrar, St Bartholomew's Hospital, London

Mr RB Combes, Head of Studies, Trinity Hospice, London

Dr JB Cookson, Glenfield General Hospital, Leicester

Dr FM Cowan, Senior Lecturer, University College London Medical School, London successful, we may see this approach more widely adopted. The ideas discussed at this meeting should inform the debate about the value of $\mathrm{PBL}$ in undergraduate medical education in the UK.

Speaking at the World Summit on Medical Education in Edinburgh in 1993, Daniel Tosteson, Dean at Harvard Medical School, said:

The most important consequence of the 'New Pathway' Programme at Harvard is the increase in attention and effort by the members of the Faculty and by the students in the strategy and tactics of medical education. In general, students welcome and enjoy the opportunity to assume greater responsibility for their own learning, and graduate with somewhat more open and inquiring minds.

Problem-based learning is just one of many strategies for learning, but Dean Tosteson's words echo the findings reported in the literature: PBL is an effective, efficient and, above all, enjoyable way of both learning - and teaching - medicine.

rs J Crosby, Curriculum Development, University of Dundee, Dundee

Ms SD Cupit, Placement Coordinator, University College London Medical School, London

Dr ALM Curran, Royal Devon \& Exeter Trust, Taunton

Dr JA Davies, Dean of Undergraduate Studies, University of Leeds, Leeds

Dr HA Davies, Department of Paediatrics, Sheffield Children's Hospital, Sheffield

Dr RG Dennick, Medical School, University of Nottingham, Nottingham

Professor T Dixon, Professor of General Practice, University of Hong Kong, Hong Kong

Dr L Edmondson, Consultant Anaesthetist/College Tutor, Wansbeck General Hospital, Wansbeck

Mr DR Edwards, British School of Osteopathy, London

Professor C Engel, Medical Education Unit, University College, London

Dr J Field, Primary Medical Care, University of Southampton, Southampton

Dr WC Finegan, Centre for Medical Education, Dundee

Dr S Fowell, Medical Education Unit, Royal Liverpool University Hospital, Liverpool

Professor Fraher, University College Cork, Republic of Ireland

Dr VM France, Medical Education Unit, University College London Medical School, London

Ms G Freeman, Education \& Training Policy Manager, NHS Executive S\&W, Bristol

Dr J Furnace, Medical Faculty Office, University of Aberdeen, Aberdeen

Dr DP Gill, Royal Free Hospital, London

Asst Professor JJ Gordon, University of Sydney, Sydney, NSW, Australia

Ms KA Greaves, Medical Undergraduate Coordinator, Rotherham General Hospital, Rotherham

Dr GW Hamlin, Postgraduate Tutor, NHS Black burn, Blackburn

Mrs NR Hartley, Hallam University, Sheffield

Dr CRK Hind, Editor - Postgraduate Medical Journal

Dr A Hunter, King's College, London

Dr DM Jelley, Collingwoode Surgery, N Shields 
Dr R Johnstone, Pasadena, CA, USA

Dr JI Koppel, Centre for Community \& Primary Health, University of Westminster, London

Mr AJ Kostrzewski, Pharmacist/Clinical Tutor, Guy's Hospital Pharmacy Directorate, London

Dr PI Kumar, SubDean, Undergraduate Students, St Bartholomew's \& Royal London Hospitals, London

Mr NB Kurkure, A \& E Services, Watford General Hospital, Watford

Ms M Lawson, Department/General Practice, King's College School of Medicine and Dentistry, London

Professor IMA Ledingham, Professor of Medical Education, Ninewells Hospital, Dundee

Dr F Lefford, Department of Anatomy, University College, London

Professor S Leinster, Department of Surgery, University of Liverpool, Liverpool

Dr M Lloyd, Department/General Practice, Royal Free Hospital School of Medicine, London

Dr G Lloyd Jones, Medical Education Unit, Royal Liverpool University Hospital, Liverpool

Professor PM Lydyard, Medical School, University College, London

Dr DAF Lynch, Consultant Physician, Blackburn Royal Infirmary, Blackburn

Dr N Marshall, Division of Pathology, University College, London

Dr KH Matheson, Hon Secretary, National Association of Clinical Tutors, London

Dr G Maudsley, Department of Public Health, University of Liverpool, Liverpool

Professor SA May, Royal Veterinary College, London

Mrs W McCombes, Regional Dental Adviser's Office, University of Aberdeen, Aberdeen

Dr RP Meakin, Department of Primary Care \& Population Sciences, Royal Free Hospital, London

Dr DJR Morgan, Postgraduate Medical Centre, Chelsea \& Westminster Hospital, London

Dr A Morton, Staff Development Unit, University of Birmingham, Birmingham

Dr E Murray, Department of Primary Healthcare, Whittington Hospital, London

Dr MWN Nicholls, President - Fellowship of Postgraduate Medicine, London

Dr PA O'Neill, University Hospital of South Manchester, Manchester

Dr HL Ooi, Medical Lecturer, Mater Misericordiae Hospital, Dublin, Republic of Ireland

Professor I Percy-Robb, Faculty of Education, University of Glasgow, Glasgow

Ms SL Phillips, Enfield \& Haringey Health Authority, London

Mr RM Price, Deputy Librarian, Wellcome Institute, London

Dr P Pulluqi, Visiting Doctor, Royal Free Hospital, London
Dr M Rickets, Department of General Practice \& Primary Care, St Bartholomew's Hospital, London

Dr L Robinson, Department of Primary Care, Medical School, Newcastle

Dr L Rrumbullaku, Visiting Doctor, Royal Free Hospital, London

Ms M Seabrook, Department of General Practice, King's College School of Medicine \& Dentistry, London

Professor W Shannon, Royal College of Surgery, Republic of Ireland

Dr F Shenfield, Department of Obstetrics and Gynaecology, Middlesex Hospital, London

Dr TSB Simons, Department of Physiology, King's College, London

Dr $R$ Snowball, User Education Manager, Cairns Library, University of Oxford, Oxford

Dr BM Southcott, Department of Radiotherapy, Charing Cross Hospital, London

Professor L Southgate, Medical School, University College, London

Mr S Stewart, Regional Dental Adviser's Officer, University of Aberdeen, Aberdeen

Mr RD Swallow, Principal Pharmacist Clinical Teaching, St James' University Hospital, Leeds

Rev Dr DCM Taylor, University of Liverpool, Liverpool

Dr JE Thistlethwaite, Senior Lecturer, Leeds University Medical School, Leeds

Professor CPM van der Vleuten, Department Educational Research, University of Limburg, Maastricht, The Netherlands

Dr MJ Vernon, Department of Health Care for the Elderly, Royal London Hospital, London

Mr M Vimpany, Lecturer, Continuing Education, University of Sheffield, Sheffield

Ms C Walker, Arnold Publishers, London

Professor HM Warenius, Director, CRC Oncology Research Unit, Liverpool

Dr V Wass, Department of Primary Care \& Medical Education, UMDS, London

Ms $\mathbf{P}$ Webb, Lecturer in Palliative Care, Trinity Hospice, London

Mrs CE Webster, Medical Education Manager, Rotherham PGME, Rotherham

Dr MS Wetzel, Harvard Medical School, Boston, MA, USA

Dr PR Wilkinson, Hon Secretary, Fellowship of Postgraduate Medicine, London

Dr DDR Williams, Consultant Psychiatrist, Glan-yMor NHS Trust, Wales

Dr EJ Wright, Consultant Anaesthetist/College Tutor, Aintree Hospitals Trust, Aughton

Dr RA Young, Tropical Medicine Resource, Wellcome Trust, London 